\title{
Yellow fever
}

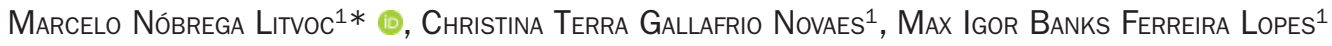

\section{SUMMARY}

The yellow fever (YF) virus is a Flavivirus, transmitted by Haemagogus, Sabethes or Aedes aegypti mosquitoes. The disease is endemic in forest areas in Africa and Latin America leading to epizootics in monkeys that constitute the reservoir of the disease. There are two forms of YF: sylvatic, transmitted accidentally when approaching the forests, and urban, which can be perpetuated by Aedes aegypti. In Brazil, the last case of urban YF occurred in 1942. Since then, there has been an expansion of transmission areas from the North and Midwest regions to the South and Southeast. In 2017, the country faced an important outbreak of the disease mainly in the states of Minas Gerais, Espírito Santo and Rio de Janeiro. In 2018, its reach extended from Minas Gerais toward São Paulo. Yellow fever has an incubation period of 3 to 6 days and sudden onset of symptoms with high fever, myalgia, headache, nausea/vomiting and increased transaminases. The disease ranges from asymptomatic to severe forms. The most serious forms occur in around $15 \%$ of those infected, with high lethality rates. These forms lead to renal, hepatic and neurological impairment, and bleeding episodes. Treatment of mild and moderate forms is symptomatic, while severe and malignant forms depend on intensive care. Prevention is achieved by administering the vaccine, which is an effective (immunogenicity at $90-98 \%$ ) and safe (0.4 severe events per 100,000 doses) measure. In 2018, the first transplants in the world due to YF were performed. There is also an attempt to evaluate the use of active drugs against the virus in order to reduce disease severity.

Keywords: Yellow Fever. Epidemiology, Brazil. Clinical Aspects. Treatment Perspectives. Vaccine.

\section{INTRODUCTION}

Yellow fever is a non-contagious infectious disease caused by an arbovirus (arthropod-borne virus) belonging to the Flaviviridae family. The disease is endemic only in the tropical forests of the African continent and Latin America, with the possibility of determining urban cycles (Figures 1 and 2). The vectors of the sylvatic form in Brazil are Haemagogus or Sabethes mosquitoes that live and feed on the treetops. Urban YF is associated with the participation of the vector Aedes aegypti, present in several Brazilian cities. ${ }^{1}$

According to the World Health Organization (WHO), the estimated number of severe cases in both continents is $84,000-170,000$, with approximately $29,000-60,000$ deaths annually. ${ }^{2}$

Yellow fever was an unknown disease until the discovery of the Americas. It probably originated in Africa and was possibly introduced to the American continent by ships carrying slaves and the vector Aedes aegypti. The first epidemic was reported in the American continent, where it is possible to characterize with greater certainty the infection by yellow fever, occurred in the Yucatán peninsula in 1648.,3

In the US, an epidemic in Philadelphia in 1793 decimated about $10 \%$ of the population. ${ }^{2}$ In 1881 , Cuban epidemiologist Carlos Finlay associated the transmission of the disease with mosquito bites. In 1900, physician Walter Reed proved this association and carried out effective measures to control the transmission by mosquitoes in the American territory.

In Brazil, the descriptions of epidemics of yellow fever date back to the $17^{\text {th }}$ century; since then, we have found several reports of seasonal activity of the disease in many localities throughout the country. Yellow fever, which was 


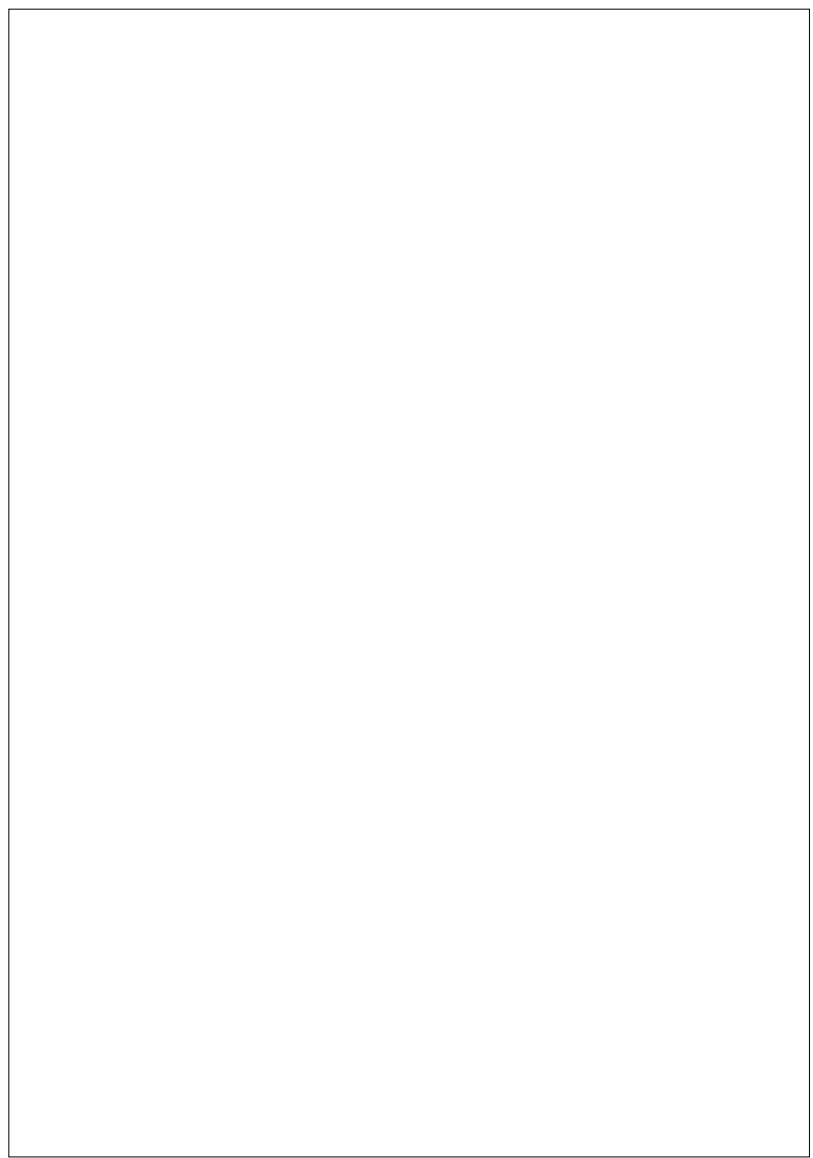

FIGURE 1 Yellow fever vaccine recommendations in the Americas. ${ }^{1}$

${ }^{1}$ Current as of September 2016. This map, which aligns with recommendations also published by the World Health Organization (WHO), is an updated version of the 2010 map created by the Informal WHO Working Group on the Geographic Risk of Yellow Fever.

${ }^{2} Y e l l o w$ fever (YF) vaccination is generally not recommended in areas where there is low potential for YF virus exposure. However, vaccination might be considered for a small subset of travelers to these areas who are at increased risk for exposure to YF virus because of prolonged travel, heavy exposure to mosquitoes, or inability to avoid mosquito bites. Consideration for vaccination of any traveler must take into account the traveler's risk of being infected with YF virus, country entry requirements, and individual risk factors for serious vaccine-associated adverse events (e.g., age, immune status).

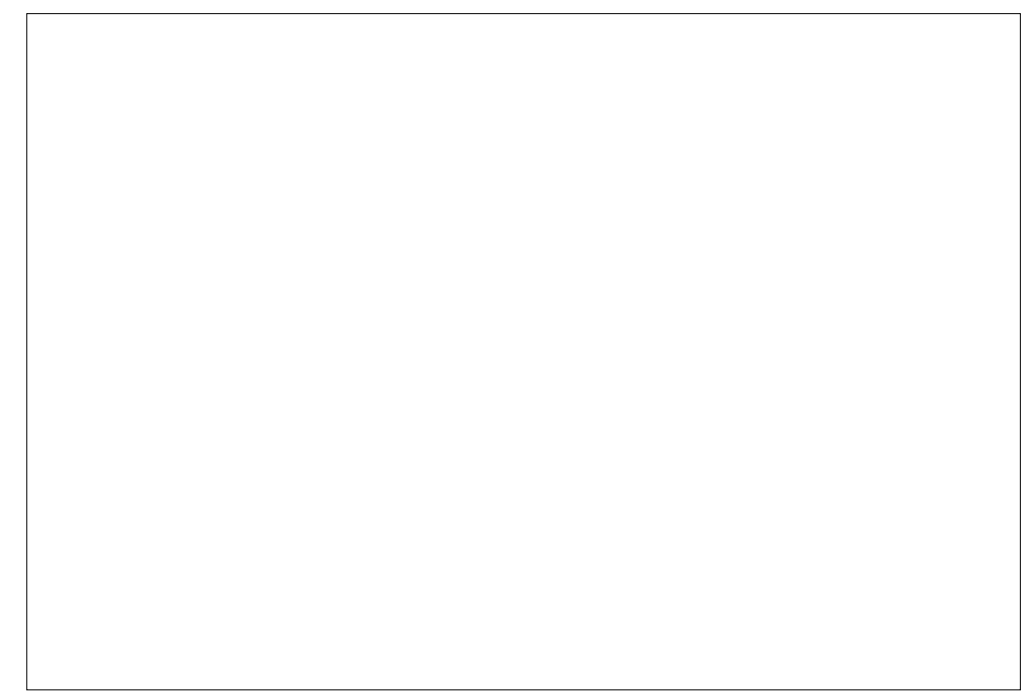

FIGURE 2 Yellow fever vaccine recommendations in Africa. ${ }^{1}$

${ }^{1}$ Current as of September 2016. This map, which aligns with recommendations also published by the World Health Organization (WHO), is an updated version of the 2010 map created by the Informal WHO Working Group on the Geographic Risk of Yellow Fever.

${ }^{2}$ Yellow fever (YF) vaccination is generally not recommended in areas where there is low potential for YF virus exposure. However, vaccination might be considered for a small subset of travelers to these areas who are at increased risk for exposure to $Y F$ virus because of prolonged travel, heavy exposure to mosquitoes, or inability to avoid mosquito bites. Consideration for vaccination of any traveler must take into account the traveler's risk of being infected with YF virus, country entry requirements, and individual risk factors for serious vaccine-associated adverse events (e.g., age, immune status). 
considered an important public health problem in Rio de Janeiro, was a challenge tackled by Oswaldo Cruz, who in 1903 was the general director of Public Health and adopted measures similar to those of the Cuban model in the fight against Aedes aegypti, known at the time as Stegomia fasciata. In 1907, after great efforts, the endemic in the city of Rio de Janeiro was considered controlled. ${ }^{5}$

The last cases of urban yellow fever in Brazil occurred in the city of Sena Madureira, state of Acre, in 1942. Since then, all reported cases are due to the accidental infection of humans when entering or approaching forest areas where the virus circulates (wild cycle). In cycles of approximately 5 to 10 years, it is possible to observe the intensification of cases in primates (epizootics) leading to a greater chance of human infection. Over the years, epizootic areas have spread to the mid-south of the country and more recently to the southeast, near densely populated areas, which increases the risk of urban reintroduction of the disease.

Recent epidemics such as those reported in Angola and the Democratic Republic of Congo between 2015 and 2016 remind us of the significant risk of local outbreaks progressing when control measures are not readily taken.

\section{Etiological agent}

The yellow fever virus is an RNA virus of the genus Flavivirus and family Flaviviridae. The virus was isolated in 1927 by Adrian Stokes of a patient from Ghana, known as Asibi. Other viruses from the same family that affect humans include: Dengue, West Nile virus, Rocio and St. Louis encephalitis. There are genotype differences among strains found on the African and South American continent. ${ }^{4}$

\section{EpIDEMIOLOGY}

Yellow fever is a disease with compulsory notification, even on simple suspicion of the disease. About $80 \%$ of the cases are in males, predominantly in the age group of $15-35$ years, which reflects a higher degree of exposure to forests.

The most common period of the disease occurs between the months of December and May, characterized by higher rainfall volume in Brazil. Currently, transmission to humans is linked to the wild cycle, which has monkeys as reservoir and mosquitoes of the genera Haemagogus (Haemagogus janthinomys and Haemagogus leucocelaenus) and Sabethes (Sabethes chloropterus and Sabethes albiprivus) as vectors. The most susceptible animals are howler monkeys, capuchin monkeys and the common marmoset. Transmission to humans is incidental, occuring most of times when people enter a forest area for extraction or recreation activities. Epizootics occur cyclically and periods of epidemiological silence probably coincide with a decrease in the number of susceptible primates.
The urban cycle involves infected humans and the Aedes aegypti vector. There have been no urban cases in the Americas since 1954, but it is still very common in African countries. An intermediate cycle was described in areas of transition to forest in Africa (savannah), with participation of monkeys, vector Aedes spp and humans.

In Brazil, after the eradication of the Aedes aegypti mosquito in 1954, the sylvatic transmission area of the virus predominantly covered the legal Amazon region (Figure 3). Over the years, the transition area has also moved to the Midwest and Southeastern states such as São Paulo, Minas Gerais and Rio de Janeiro, as well as the southern states of Paraná, Santa Catarina and Rio Grande do Sul.

In December 2016, the Brazilian Ministry of Health reported cases of sylvatic yellow fever in the state of Minas Gerais, with rapid expansion in the first six months of the outbreak to the states of Espírito Santo, São Paulo, Bahia and Rio de Janeiro. In the first half of 2017, there were 3,564 suspected cases of sylvatic yellow fever. Of these, 777 (21.8\%) were confirmed, 2,270 (63.7\%) ruled out, 213 (6.0\%) were still being investigated, and 304 (8.5\%) were considered inconclusive.

After the Brazilian Ministry of Health declared the end of the transmission of new cases on September $6^{\text {th }}$, 2017 new autochthonous cases began to be notified as of epidemiological week number 38/2017 in the state of São Paulo (Figures 3, 4 and 5).

According to official CVE-SP (Center for Surveillance and Epidemiology - São Paulo) data, from January 2017 to February $14^{\text {th }}, 2018$ there have been 183 confirmed autochthonous cases, with 64 deaths, resulting in a mortality rate of $35 \%$. The majority of cases occur in males (83.1\%) and the median age is 43 years (2-89 years). Many cases are still being investigated. ${ }^{6} \mathrm{New}$ cases have also been confirmed in Minas Gerais (77) and Rio de Janeiro (27).

\section{INCUBATION PERIOD}

The mean time between being bitten by the infected mosquito and the onset of the first symptoms is 3-6 days s.7, $^{2,7}$ and may reach $10-15$ days. $^{8}$

\section{Clinical manifestation}

Half of those infected are estimated to be asymptomatic. ${ }^{8}$ Yellow fever is described as a biphasic disease: ${ }^{7}$

- Viremic phase: high fever, with a mean duration of three days, ${ }^{9}$ myalgia, headache, lack of appetite and nausea. Mostly, these symptoms subside within 2 to 4 days, characterizing mild and moderate cases, which are estimated to account for $20-30 \%$ of infected patients. ${ }^{8}$

- Toxemic phase: takes place in approximately $15 \%$ of patients ${ }^{2,7,10}$ and begins after a period of clinical improve- 


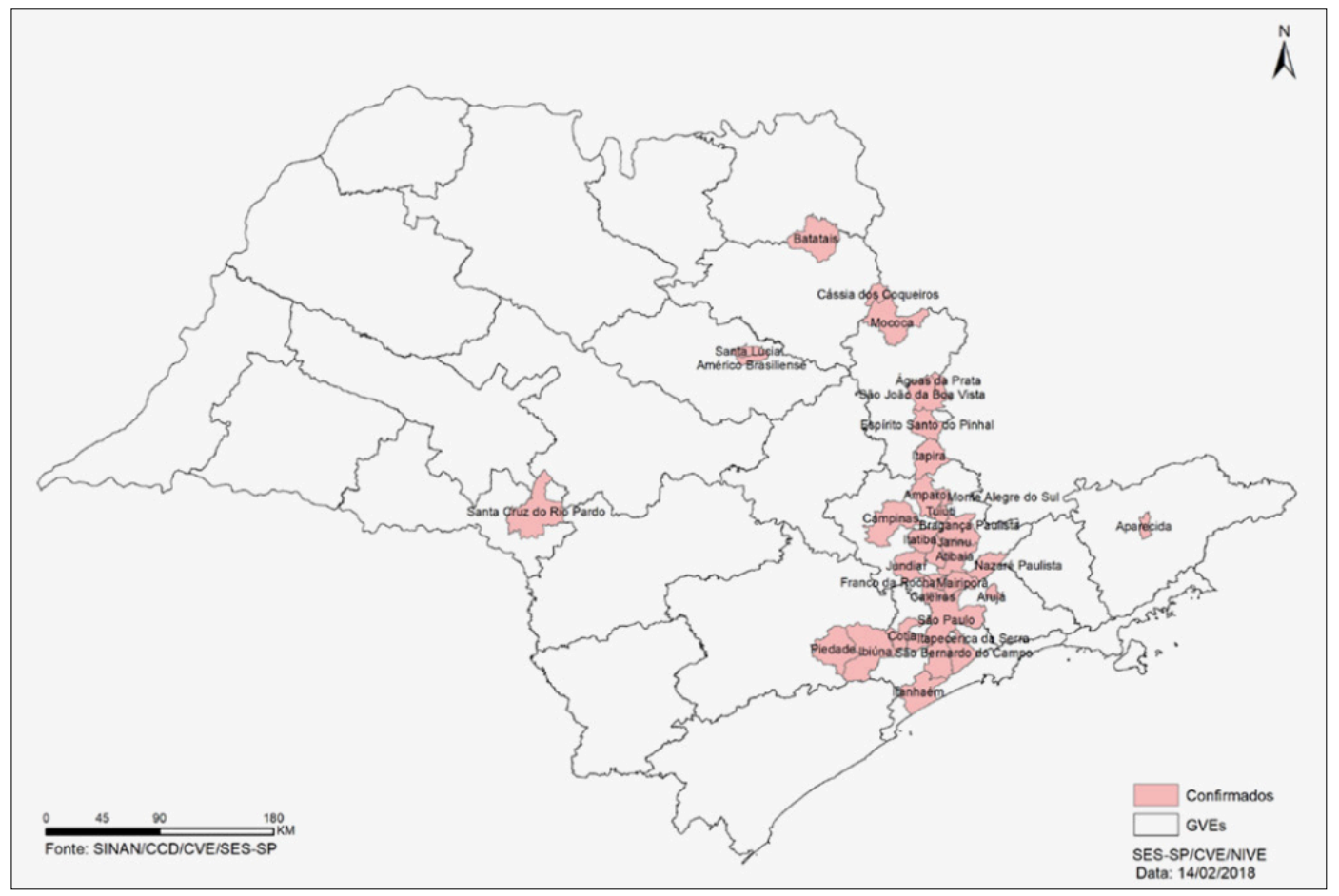

FIGURE 3 Distribution of autochthonous yellow fever cases by municipality (origin of infection). State of São Paulo, $2017-2018$.

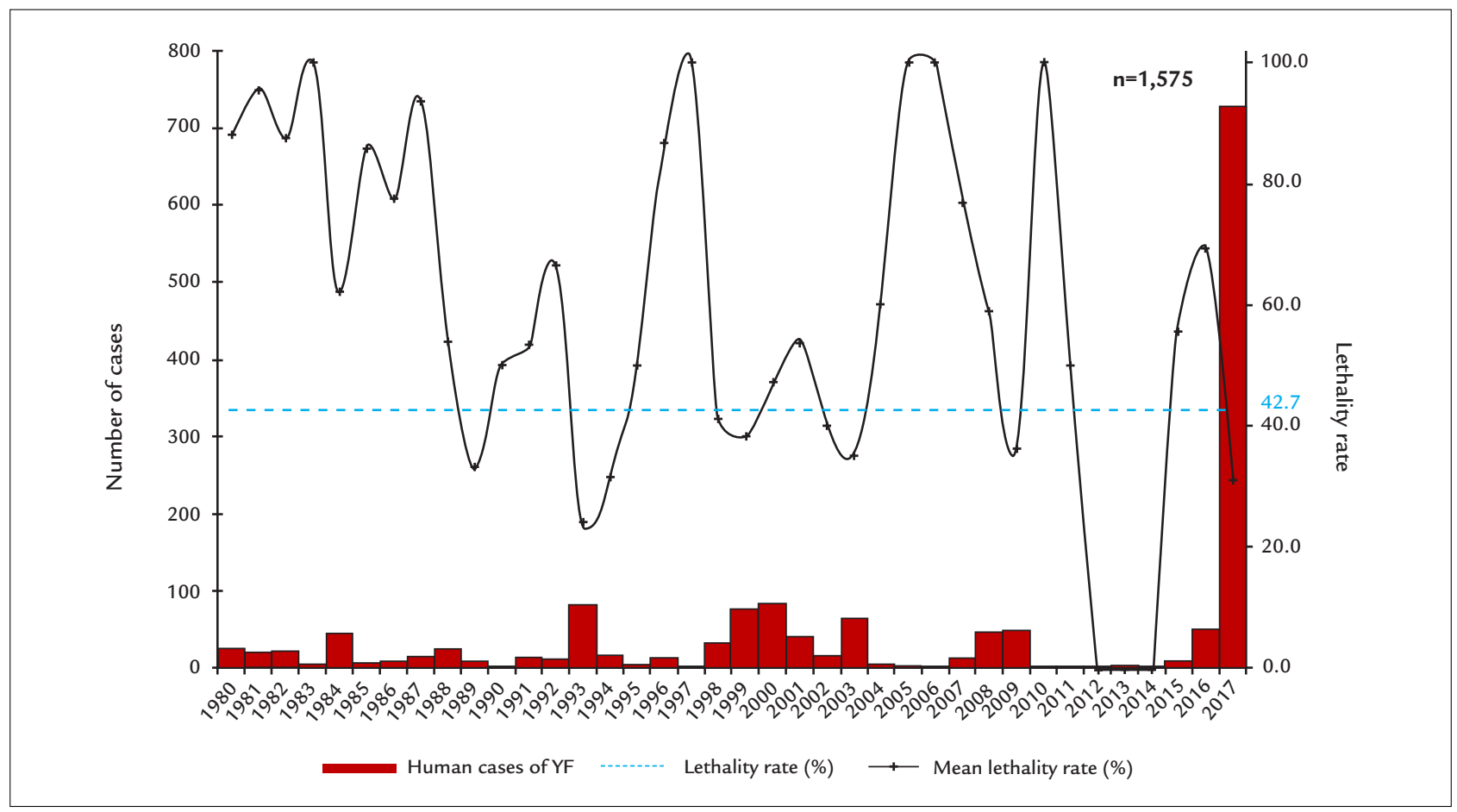

FIGURE 4 Historical series of the number of confirmed human cases of YF and lethality according to the year of onset of symptoms, Brazil, from 1980 to June 2017. 


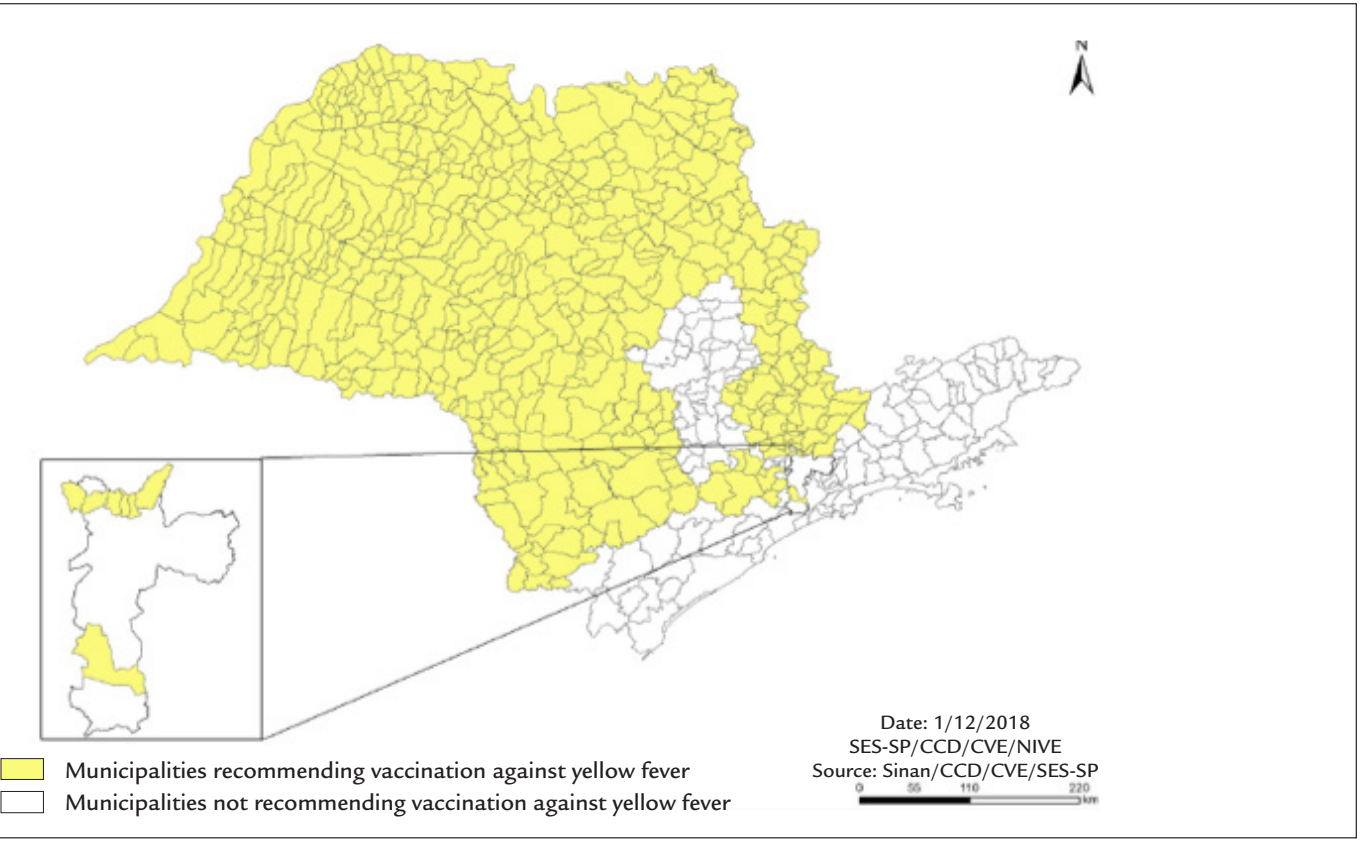

FIGURE 5 Municipalities in the state of São Paulo and Administrative Districts of the capital currently recommending vaccination against yellow fever. State of São Paulo, 2018.

ment that follows the first phase, lasting 24 hours on average. ${ }^{9}$ It is characterized by recrudescence of high fever, chills, worsening of headache and myalgia, and involvement of various organs and systems. It is in this second phase that, later on, icteric discoloration of the skin that characterizes the disease develops. There may be bleeding, kidney dysfunction with oliguria, ${ }^{11}$ as well as cardiovascular dysfunction and neurological impairment with seizures. ${ }^{7,8,10}$ Often, the unusual pairing of fever with bradycardia (Faget sign) is observed. ${ }^{8-10}$ Up to half of these patients progress to death in 10 to 14 days, and the rest recover without significant sequelae. ${ }^{7,8}$

During the outbreak in São Paulo, some patients who progressed to severe disease (mainly elderly) did not develop fever at any time (personal observation of the authors).

It should be noted that the notification must be made on suspicion, as it is COMPULSORY and IMMEDIATE, and must be informed by telephone, fax or e-mail to the local responsible agency. ${ }^{8}$

\section{LABORATORY CHANGES}

The main changes are listed below.

Leukopenia is characteristic (leukocytes between 1,500 and 2,500 cells $/ \mathrm{mL}$, plus relative neutropenia ${ }^{9}$ ) both in the early and late phases; however, leukocytosis is sometimes seen in a later period. ${ }^{10} \mathrm{C}$-reactive protein is generally low, even in patients who progress to death. Hyper- bilirubinemia usually occurs more intensely at the end of the first week, and appears after an increase in transaminases. The observed levels of AST and ALT in severe cases are often above $5,000 \mathrm{IU} / \mathrm{L}$, sometimes reaching more than 20,000 IU/L, levels rarely seen in other causes of hepatitis. AST values are usually higher than ALT values. Both creatinine and urea levels rise frequently and their worsening correlates with deterioration of the patient's condition.

\section{Classification}

The clinical picture can be classified as mild, moderate, severe or malignant. ${ }^{8}$ In mild and moderate forms, the symptoms and laboratory changes are less intense, with mild thrombocytopenia and moderate increase in transaminases. In this form, there is usually no increase in bilirubin. Severe disease, on the other hand, leads to intense thrombocytopenia and increased transaminases, in addition to increased creatinine. Malignant yellow fever is that in which disseminated intravascular coagulation is observed with fibrinogen consumption and accumulation of D-dimer, in addition to the previous alterations. ${ }^{8}$

\section{TREATMENT}

To date, there is no specific antiviral against yellow fever.

In mild cases (Table 1), outpatient follow-up with daily visits can be implemented, provided that there is quick access to health services and someone at home who can observe the patient. It is important to alert patients 
with suspected yellow fever that there may be a rapid worsening of the condition. In such cases, only symptomatic medications with no potential action on the liver, such as dipyrone (avoiding NSAIDs and paracetamol, due to the risk of hepatotoxicity), and adequate hydration $(60 \mathrm{~mL} / \mathrm{kg} /$ day $)$ are recommended. ${ }^{8}$

Other patients (moderately severe and severe cases) should be hospitalized. For patients hospitalized in infirmary wards, the following is recommended: thorough control of diuresis, with an ideal flow of $>1 \mathrm{~mL} / \mathrm{kg} / \mathrm{h}$, with clinical reassessments at least every 4 hours; and daily laboratory tests or if there is any sign of clinical worsening. ${ }^{4}$ In this case, it is important to keep the patient euvolemic. If there is any sign of dehydration, it is recommended to initiate intravenous fluid replacement with $0.9 \%$ saline boluses of $10 \mathrm{~mL} / \mathrm{kg}$ in the first hour, with subsequent reassessment of vital signs and diuresis and, if necessary, maintenance with $30 \mathrm{~mL} / \mathrm{kg} /$ day or a sufficient volume of fluids to maintain adequate diuresis. ${ }^{8}$

Patients with the malignant form may progress with a need for endotracheal intubation and protective mechanical ventilation due to upper gastrointestinal bleeding, lowered level of consciousness or respiratory failure. Dialysis is often necessary. Use of routine gastric protectors and transfusion of fresh frozen plasma $(10 \mathrm{mg} / \mathrm{kg})$ in cases of bleeding or intense coagulopathy is also recommended. ${ }^{8}$

\section{DiagnOSIS}

Clinically, it is difficult to differentiate it from other viral diseases in the initial phase, and yellow fever should be considered in all cases with compatible clinical manifestations, even if mild, and positive epidemiology (having visited a risk area within 15 days prior to the onset of symptoms without being previously vaccinated, or having been vaccinated within less than 30 days $^{8}$ ).

Yet, in patients who evolve more severely, some clinical and laboratory characteristics lead us to suspect more readily of yellow fever, such as a rapid increase (in a matter of 2-3 days) of the transaminases to very high levels, with a predominance of AST compared to ALT, ${ }^{8,11}$ which is the opposite of that seen in classical viral hepatitis, perhaps reflecting skeletal and myocardial muscle cell involvement. ${ }^{11}$ As observed in the São Paulo outbreak, laboratory worsening tends to precede clinical worsening.

Confirmation of the diagnosis is made using a method of molecular amplification of the virus in the blood (highly sensitive and specific method, which may even allow to differentiate the sylvatic virus from the vaccine strain ${ }^{11}$ ), which classically occurs up to the fifth day of the disease. ${ }^{8}$ It should be noted, however, that, in some patients, viremia seems to persist longer, sometimes until after the $10^{\text {th }}$ day.

As of day 5, serology (detection of IgM and IgG, specific for yellow fever) is recommended. ${ }^{8}$ Serology, how-

TABLE 1 Classification table according to clinical picture, expected laboratory changes and treatment for cases of suspected or confirmed yellow fever.

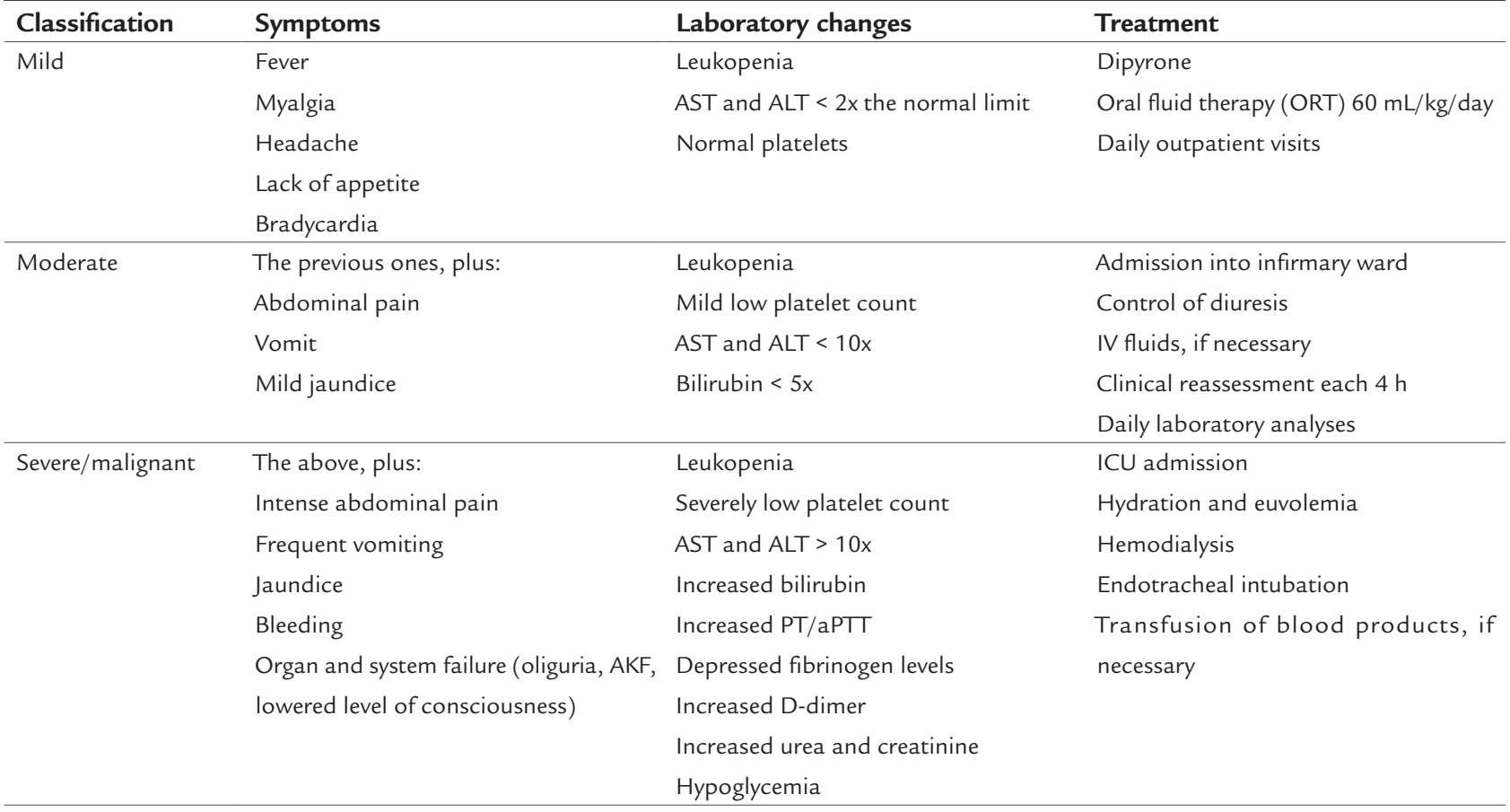

AST: aspartate aminotransferase; ALT: alanine aminotransferase; PT: prothrombin time; aPTT: activated partial thromboplastin time; ICU: intensive care unit; IV: intravenous. 
ever, can cross-react with other flaviviruses, such as dengue virus ${ }^{10,11}$ or simply indicate a response to recent vaccination for yellow fever. In case of death, the diagnosis can be confirmed in several tissues in up to 24 hours; ${ }^{8}$ or by immunohistochemistry. 8,10

\section{Treatment PERSPectives}

This year at Hospital das Clínicas da FMUSP, the first YF-related liver transplant was performed, followed by four more in patients with malignant yellow fever who progressed to complete liver failure. At this point, the role of liver transplantation in treating severe forms of yellow fever, or the correct timing for this, has not yet been established. Criteria such as hepatic encephalopathy and factor $\mathrm{V}<20$ or $30 \%$ (if the patient is younger or older than 30 years, respectively) for indication of transplantation is currently being discussed.

Clinical and laboratory research is underway for antiviral testing against yellow fever virus, such as sofosbuvir (now used for treatment of hepatitis C). ${ }^{12}$

\section{Differential diagnosis}

Leptospirosis (of all, the disease most similar to yellow fever ${ }^{9}$ ), malaria, dengue, mononucleosis, influenza, viral hepatitis, rickettsiosis, Zika (in mild early phases), chikungunya, sepsis and typhoid fever. ${ }^{1}$

\section{FolLOW-UP}

The Brazilian Ministry of Health recommends hospital discharge based on the following criteria: patient afebrile for $>24$ hours with at least 10 days of illness or afebrile for $>3$ days, regardless of disease duration, in both cases with progressive improvement of transaminases and platelets. ${ }^{8}$
Convalescence, with prolonged asthenia, may last up to 8 weeks, with transaminase oscillations (ALT prevailing at this stage) and even transient increases in bilirubin. There is no need for future vaccination, as the patient is considered protected. ${ }^{8}$

\section{YeLLOW FEVER VACCINE}

Prevention is based on the use of attenuated live virus vaccine from strain 17D, developed in 1937 by Max Theiler, a virologist who received the Nobel Prize in Medicine in 1951 . The vaccine is considered safe $(1,255$ severe adverse events for 333 million doses applied $\left.{ }^{13}\right)$ and highly effective (immunogenicity between $90 \%$ and $98 \%$ after day $10^{8}$ ). Since 2013 , the $\mathrm{WHO}$ has reviewed the need to repeat additional doses every 10 years. ${ }^{14}$ Currently, only a single dose is indicated throughout life. In immunocompromised populations such as people living with HIV/ AIDS, women vaccinated while pregnant and children under 5 years of age, there may be changes in the recommendations in the near future. However, the main contraindication is related to the use of immunosuppressive drugs at the time of vaccination or weeks before receiving the vaccine (Table 2).

During the 2015 and 2016 epidemic in Angola and the Federative Republic of Congo, the fractional dose of the vaccine was chosen to protect large numbers of people, with a good response to restrain the epidemic. ${ }^{15}$

This strategy was also adopted in 2018 for the vaccination of part of the population in the states of São Paulo, Rio de Janeiro and Bahia. Studies suggest that the use of fractionated doses ( $1 / 5$ of the usual dose) leads to the production of neutralizing antibodies at levels equivalent to that of the conventional dose..$^{15}$ The durability of this pro-

\section{TABLE 2 Vaccine recommendation by the Brazilian Ministry of Health. ${ }^{8}$}

\begin{tabular}{|c|c|c|}
\hline Recommended & Contraindicated & With caution ${ }^{* * *}$ \\
\hline $\begin{array}{l}\text { People residing or traveling to areas } \\
\text { with vaccine recommendation* }\end{array}$ & $\begin{array}{l}\text { Cancer patients on chemotherapy or radiotherapy } \\
\text { Immunosuppressive or immunomodulating drugs } \\
\text { Steroids, depending on dose and length of use }{ }^{* *}\end{array}$ & $\begin{array}{l}\text { Those aged }>60 \text { years who have never been vaccinated } \\
\text { Pregnant or lactating women with infants }<6 \text { months } \\
\text { Breastfeeding women should stop breastfeeding for }\end{array}$ \\
\hline AND & $\begin{array}{l}\text { Patients who underwent bone marrow or solid organ } \\
\text { transplantation }<2 \text { years }\end{array}$ & $\begin{array}{l}10 \text { days after vaccination } \\
\mathrm{HIV}+\text { patients with CD } 4>350 \text { cells } / \mathrm{mm}^{3} \text { (require more }\end{array}$ \\
\hline Age $>9$ months and $<60$ years & $\begin{array}{l}\text { Previous thymus disease (myasthenia gravis, thymoma) } \\
\text { Systemic lupus erythematosus }\end{array}$ & $\begin{array}{l}\text { attention if CD } 4 \text { between } 200 \text { and } 350 \text { cells } / \mathrm{mm}^{3} \text { ) } \\
\text { Autoimmune diseases }\end{array}$ \\
\hline AND & Rheumatoid arthritis & Hematologic diseases \\
\hline No contraindications & $\begin{array}{l}\text { Primary immunodeficiencies } \\
\text { Advanced HIV infection }\left(C D 4<200 \text { cells } / \mathrm{mm}^{3} \text { ) }\right. \\
\text { Infants under } 6 \text { months of age } \\
\text { Individuals with a history of anaphylactic reaction } \\
\text { related to substances present in the vaccine }\end{array}$ & $\begin{array}{l}\text { Patients who underwent bone marrow } \\
\text { transplantation }>2 \text { years, stable, with no graft } \\
\text { versus host disease (GVHD) }\end{array}$ \\
\hline
\end{tabular}

* List of Brazilian municipalities with vaccine recommendation:

<http://portalarquivos2.saude.gov.br/images/listavacinacaofa.pdf>

** Equivalent to $20 \mathrm{mg}$ or more of prednisone for $>14$ days; or pulse therapy.

*** Cases where the administration of the vaccine is conditional on individual medical risk-benefit assessment. 
tection is not certain. In a Bio-Manguinhos/Fiocruz study, the fractional dose vaccine continued to provide protection after 8 years. Those vaccinated with the fractionated dose do not receive an international yellow fever vaccination certificate and, therefore, if a certificate is necessary, they must request the standard dose.

\section{References}

1. Vasconcelos PFC. [Yellow fever]. Rev Soc Bras Med Trop. 2003; 36(2):275-93.

2. Paules CI, Fauci AS. Yellow fever - Once again on the radar screen in the Americas. N Engl J Med. 2017; 376(15):1397-9.

3. Staples JE, Monath TP. Yellow fever: 100 years of discovery. JAMA. 2008; 300(8):960-2.

4. Wang E, Weaver SC, Shope RE, Tesh RB, Watts DM, Barrett AD. Genetic variation in yellow fever virus: duplication in the 3 ' noncoding region of strains from Africa. Virology. 1996; 225(2):274-81.

5. Franco O. História da febre amarela no Brasil. Rio de Janeiro; 1969 . Available from: http://bvsms.saude.gov.br/bvs/publicacoes/0110historia_febre.pdf.

6. Secretaria do Estado da Saúde (SP). Coordenadoria de Controle de Doenças. Boletim Epidemiológico Febre Amarela - 29/01/2018 [cited 2018 Feb 03].
Available from: http://www.saude.sp.gov.br/resources/cve-centro-devigilancia-epidemiologica/areas-de-vigilancia/doencas-de-transmissao-porvetores-e-zoonoses/doc/famarela/fa18_boletim_epid_2901.pdf.

7. World Health Organization. Yellow fever [cited 2018 Jan 31]. Available from: http://www.who.int/csr/disease/yellowfev/en/.

8. Ministério da Saúde (BR). Febre amarela: guia para prossionais de saúde. Brasília (DF); 2018 [cited 2018 Feb 03]. Available from: http://portalarquivos2. saude.gov.br/images/pdf/2018/janeiro/18/Guia-febre-amarela-2018.pdf.

9. Monath TP. Yellow fever: an update. Lancet Infect Dis. 2001; 1(1):11-20.

10. Centers for Disease Control and Prevention. Clinical and Laboratory Evaluation. Yellow Fever [cited 2018 Jan 31]. Available from: https://www.cdc.gov/ yellowfever/healthcareproviders/healthcareproviders-clinlabeval.html.

11. Monath TP, Vasconcelos PF. Yellow fever. J Clin Virol. 2015; 64:160-73.

12. Freitas C, Higa L, Sacramento C, Ferreira A, Reis P, Delveccio R et al. Yellow fever virus is susceptible to sofosbuvir both in vitro and in vivo. BioRxiv preprint posted online Feb. 15, 2018. Available from: https://doi.org/10.1101/266361

13. Staples JE, Bocchini JA Jr, Rubin L, Fischer M; Centers for Disease Control and Prevention (CDC). Yellow fever vaccine booster doses: recommendations of the Advisory Committee on Immunization Practices, 2015. MMWR Morb Mortal Wkly Rep. 2015; 64(23):647-50.

14. Vaccines and vaccination against yellow fever. WHO position paper - June 2013. Wkly Epidemiol Rec. 2013; 88(27):269-83.

15. Yellow fever vaccine: WHO position on the use of fractional doses - June 2017. Wkly Epidemiol Rec. 2017; 92(25):345-50. 